\title{
Por una educación para la ciudadanía global ¿desde un enfoque STEM?
}

\author{
iD Araceli SERANTES-PAZOS \\ ECIGAL-Universidad de Coruña \\ araceli.serantes.pazos@udc.es \\ https://orcid.org/oooo-0oo2-2849-6445
}

\author{
P Patricia DIGón-REGUEIRO \\ ECIGAL-Universidad de Coruña \\ patricia.digon@udc.es \\ https://orcid.org/oooo-0oo1-6711-9047
}

\section{Laura CRUZ-LÓPEZ}

ECIGAL-Universidad de Coruña

laura.cruz@udc.es

https://orcid.org/oooo-0oo2-9321-9989

\author{
Renée DEPALMA \\ ECIGAL-Universidad de Coruña \\ r.depalma@udc.es \\ https://orcid.org/oooo-0oo1-7927-321X
}

\author{
Rosa-María MÉNDEZ-GARCÍA \\ ECIGAL-Universidad de Coruña \\ rosa.mendez@udc.es \\ https://orcid.org/oooo-0oo2-2547-2819
}

\section{María BARBA NÚÑ̃EZ}

ECIGAL-Universidad de Coruña

maria.barba@udc.es

https://orcid.org/oooo-0oo2-8215-6636

\begin{abstract}
En esta era, que denominamos antropoceno, resulta inevitable preguntarnos cómo educar en una realidad líquida y global, con más incertezas que certidumbres, con mayores niveles de desigualdad e inequidad, con la amenaza de colapsos, tanto de los ciclos naturales que nos sustentan como de nuestro sistema de desarrollo, basado en la explotación de recursos finitos: cómo conectar la escuela con la realidad "glocal" para que el alumnado esté informado debidamente, sea un ciudadano comprometido en la resolución de los problemas comunes y participe en construir sociedades más justas. El reto de educar a la infancia y juventud del siglo XXI para enfrentarse a este escenario, tan desconocido como ambiguo, pasa por cuestionar la mirada eurocéntrica, colonial, patriarcal, aporofóbica y biofóbica que, en mayor o menor medida, sigue impregnando los contenidos y prácticas escolares. Significa revisar qué y cómo se crea y se trasmite el conocimiento, abrir las puertas a otras cosmovisiones y formas de adquirir saberes y destrezas, sin perder la perspectiva del para qué, es decir, sociedades empáticas, equitativas, inclusivas, multiculturales, biofílicas y no violentas. Significa también reconocer que el alumnado tiene derecho a conocer alternativas y otras miradas ante la verdad única o, en palabras de Chimamanda Ngozi Adichie (2018), el peligro de la "historia única".
\end{abstract}

La educación para la ciudadanía global (ECG) aboga por una formación integral en un mundo globalizado, que aporta conocimientos, estrategias, habilidades y principios éticos para que el alumnado pueda enfrentarse a los problemas socioambientales locales y globales, teniendo en cuenta los desafíos que tenemos como humanidad, con múltiples identidades. Frente a un currículo dominado por competencias instrumentales, impuestas a través de las Leyes por imperativo económico, se trata de una estrategia de transformación ecosocial basada en el conocimiento profundo -desde 
marcos de referencia como la pedagogía crítica o el decrecimiento-, a través de metodologías experienciales, más horizontales y globales-como el aprendizaje colaborativo, por proyectos o el aprendizaje y servicio, entre otras-, para enfrentarse a problemas reales. Los Derechos Humanos y Ios ODS son su marco de referencia.

Como grupo de investigación ECIGAL (Educación para la Ciudadanía Global), hemos comprobado que, al menos en Galicia, el enfoque para la ciudadanía global en las aulas está liderado por aquellas ONGD que encuentran profesorado sensibilizado, que les dejan "unas horas" para introducir propuestas sobre alguno de los temas de referencia -16 temáticas clave (DePalma, 2019, p. 155) o 8 aspectos clave (Bourn, 2016, p. 122)-. Una vez más, depende del activismo del profesorado, ante un compromiso diluido de las administraciones que legislan al respecto sin concretar cómo y sin dotar de presupuestos. Esto las convierte en actuaciones sin continuidad y de bajo impacto curricular, al tratarse de forma fragmentada y puntual.

Inicialmente se ponía énfasis en estas temáticas, que permanecen como referencias; en la actualidad se centra más en la forma de abordar estas cuestiones sociales y morales y en cómo se relacionan con las experiencias personales del estudiantado. En este sentido, constituye un referente la experiencia del Reino Unido, que introdujo a finales del siglo XX la educación global en la escuela través de guías curriculares y la creación de una red de escuelas, a la que se dotó de una financiación y recursos propios (Digón, 2019). En la actualidad, la LOMLOE abre las puertas a introducir esta perspectiva de forma modular:

\footnotetext{
"la educación para el desarrollo sostenible y la ciudadanía mundial ha de incardinarse en los planes y programas educativos de la totalidad de la enseñanza obligatoria, incorporando los conocimientos, capacidades, valores y actitudes que necesitan todas las personas para vivir una vida fructífera, adoptar decisiones fundamentadas y asumir un papel activo -tanto en el ámbito local como mundial- a la hora de afrontar y resolver los problemas comunes a todos los ciudadanos del mundo" (BOE, 2020, p. 6).
}

También, hemos identificado que esta perspectiva se desarrolla, en el mejor de los casos, en áreas de conocimiento relacionadas con las ciencias sociales, ética, religión y educación ciudadana o, en el peor, por su bajo impacto, en horarios no académicos (tutorías, actividades extraescolares, festivales...). El profesorado de matemáticas, tecnología, ciencias, lenguas o artes no se siente interpelado. Ante esta realidad, hemos recurrido a la cartografía social y entrevistas en profundidad para identificar experiencias inspiradoras, que aúnen las áreas didácticas que tienen más peso curricular y ECG. A la vez, buscamos comprender las resistencias y problemas para trabajar desde este paradigma.

En este sentido, compartimos que STEM es un escenario idóneo porque, como movimiento educativo, conjuga la innovación pedagógica con la renovación social (Segarra et al., 2018). Autoras como Laura Colucci-Gray, Pamela Burnard, Donald Gray y Carolyn Cooke (2019) establecen una similitud entre el humanismo renacentista y este enfoque, en el que se generan interacciones y sinergias entre las ciencias y las humanidades, permitiendo integrar agendas de inclusión social, participación comunitaria o sostenibilidad, de forma modular o interdisciplinar. Los conocimientos que el alumnado adquiere en estas disciplinas son fundamentales para que sean "una juventud más ambiciosa, más inteligente, honesta, trabajadora, informada, rebelde y contestaria" (Navarra, 2021, p. 70). En 
nuestra corta trayectoria hemos comprobado que es el profesorado el verdadero agente de innovación y cambio; además, es el que mejor comprende los contextos particulares del aula y de su alumnado, lo que le capacita para adaptar estrategias didácticas adecuadas y establecer relaciones de cooperación con otros docentes y con las ONGD, especialistas y firmes aliados.

El enfoque de ECG desde las disciplinas STEM puede promover métodos de aprendizaje participativos, con enfoques críticos y dialógicos, que generen habilidades -no solo instrumentales- y otras formas de alfabetización más respetuosas con la diversidad (individual y cultural) y la biodiversidad, reclamando así "los derechos de nuestros jóvenes a ser informados debidamente de dónde viven y de qué pueden hacer para modelar la realidad según sus preferencias y necesidades" (Navarro, 2021, p. 97). El mapa digital de experiencias de ECG puede ser un recurso que invite al profesorado de estas disciplinas a mostrar su práctica y generar referentes a imitar; en la actualidad sólo recoge experiencias desarrolladas en Galicia, pero estamos ampliando el foco a nivel estatal, gracias a las aportaciones del profesorado, especialistas universitarios y ONGD de todas las comunidades autónomas (https://emapic.es/custom/epd-experiencias).

\section{Referencias}

BOE (2020). Ley Orgánica 3/2020, de 29 de diciembre, por la que se modifica la Ley Orgánica 2/2006, de 3 de mayo, de Educación. https://www.boe.es/eli/es/lo/2020/12/29/3/con

Colucci-Gray, L., Burnard, P., Gray, D. y Cooke, C. (2019). A critical review of STEAM (Science, Technology, Engineering, Arts, and Mathematics). Oxford research encyclopedia of education. https://doi.org/10.1093/acrefore/9780190264093.013.398

DePalma, R. (2019). El proyecto investigación-acción participativa. Producir conocimiento de forma colaborativa, práctica y reflexiva. En R. DePalma (Coord.), La educación para el desarrollo y la ciudadanía global. Una experiencia de investigación-acción participativa (pp. 147-161). Graó.

Digón, P. (2019). Avances y retrocesos en la educación para el desarrollo y la ciudadanía global en Inglaterra. En R. DePalma (Coord.), La educación para el desarrollo y la ciudadanía global. Una experiencia de investigación-acción participativa (pp. 33-50). Graó.

Navarra, A. (2021). Prohibido aprender. Un recorrido por las leyes de educación en democracia. Anagrama. Ngozi Adichie, C. (2018). El peligro de la historia única. Random House.

Segarra, V. A., Natalizio, B., Falkenberg, C. V., Pulford, S. y Homes, R. M. (2018). STEAM: Using the arts to train well-rounded and creative scientists. Journal of Microbiology \& Biology Education, 19(1), 19.1.53. https://doi.org/10.1128/jmbe.v19i1.1360 